\title{
A GENERAL EQUILIBRIUM MODEL OF HETEROGENEOUS LOCAL PROPERTY TAXES
}

\author{
Paul N. COURANT* \\ The University of Michigan, Ann Arbor, MI 48109, U.S.A.
}

Received January 1977, revised version received June 1977

\begin{abstract}
A formal model of an economy consisting of many production centres, each of which levies property taxes at a diffcrent rate, is developed and analyzed. In the context of the model, it is shown that holders of capital may have either a positive or negative willingness to pay for a heterogenous system of taxes relative to a uniform tax which raises the same revenue. Particular emphasis is placed on interpretation of the 'new view' of the property tax in light of this and other results which derive from the model.
\end{abstract}

\section{Introduction}

The key insight in the 'new view' of the property tax is that the impact of local taxes on an economy as a whole will be very different from the impact of differences in such taxes across localities within an economy. ${ }^{1}$ The effects of property taxes, then, derive both from the general level of property taxation (which is seen as being borne by capital everywhere in the system) and from variation in local tax rates, which cause excise effects. The incidence of these excise effects is unknown a priori, as is generally the case with taxes that are potentially shiftable.

Precise theoretical propositions concerning the relationships between these excise effects and the economy-wide effects of local taxation require an explicit general equilibrium model of an economy in which there are many cities which impose property taxes at different rates. The major purpose of this paper is to develop and analyze such a model, with a specific application to property taxation. In so doing, the paper will clarify the economic significance of the 'average' property tax rate in the 'new view'. It will be shown that the average

*I am grateful to the members of the seminar in economic theory at The University of Michigan, and most especially Theodore C. Bergstrom for helpful comments on an earlier version of this paper. In addition, I acknowledge the perceptive comments of Harvey Brazer, Alan Deardorff, Edward Gramlich and John Laitner. The model used in this paper derives in part from work done jointly with Daniel L. Rubinfeld, to whom I owe a considerable intellectual debt. Both referees and A. B. Atkinson made useful comments on the penultimate draft. With all of this talented assistance, anything still wrong must be my fault.

${ }^{1}$ The 'new view' of the property tax was developed by Mieszkowski $(1969,1972)$ following from Harberger's work on the corporate income tax (1962), and appears to be well on its way to becoming orthodoxy, as expressed by Aaron (1975), among others. 
tax rate which is computed by weighting local tax rates by physical quantities of capital will not suffice either as a generally accurate measure of the tax burden borne by capital or a benchmark for computing excise effects. ${ }^{2}$ Further, it will be shown that the error in this measure can be either positive or negative, and that under ccrtain circumstances it can be quite large relative to total tax revenue in the system.

This result may have considerable policy significance in light of recent court decisions (notably the Serrano decision) which have led to proposals that States assume responsibility for education finance. An important implication of this paper is that implementation of a state administered property tax at the average of rates levied by localities will in general change the distribution of tax incidence across factors. Furthermore, it will change the equilibrium distribution of city sizes - and cities which currently levy taxes at the average rate may either grow or shrink.

The paper is organized as follows. Section 2 presents a formal model of an economy with many taxing jurisdictions. In section 3 the model is employed to derive propositions concerning the incidence and excess burden of heterogeneous property taxes. It is shown that in general there exists no uniform tax rate which would balance the public budget and impose the same burden on capital as that deriving from a given system of heterogeneous local tax rates. Section 4 derives conditions which determine incidence and presents numerical examples for the CES case. Section 5 discusses some policy implications of the above exercises, and suggests ways in which the model might be improved.

\section{The formal model ${ }^{3}$}

Assumption 1. There is a fixed stock of capital $\bar{K}$ available to the economy which is closed.

This assumption is standard in discussions of the 'new view' and indeed in all discussions of general equilibrium tax incidence following from Harberger (1962). To the extent that capital is mobile across economies (or otherwise elastically supplied) the quantity of capital actually employed would have to be endogenously determined within the model, which would greatly complicate the analysis. Whike the issues raised by the possibility of international capital mobility may have important implications for our understanding of the effects of taxes on capital, they will be ignored here. ${ }^{4}$ Assumption 1 implies that if the marginal product of capital is positive all of the capital in the system $(\bar{K})$ will be employed.

\footnotetext{
${ }^{2}$ See Mieszkowski (1972, pp. 79-80), and Aaron (1975, pp. 38-55), for discussions of the role of the average tax and its relation to excise effects.

${ }^{3}$ The model presented in this section is an extension and generalization of the model used in Courant and Rubinfeld (1978).

${ }^{4}$ Alternatively, the model may be considered as a model of the world economy.
} 
Assumption 2. There exist $N$ locations within the economy, indexed $i=1, \ldots, N$, in which production is feasible and in which there is a fixed, strictly positive stock of land, $L_{i}$.

Assumption 3. The production technology at each location $i$ is given by $q_{i}=f_{i}\left(K_{i}\right)$, where $q$ is a homogeneous consumption good and each $f_{i}(\cdot)$ is increasing, strictly concave, and twice differentiable, and $f_{i}(0)=0$.

The purpose of assumptions 2 and 3 is to assure that it is sensible for there to exist a competitive equilibrium in which localities tax at different rates and production still takes place in those localities where rates are high. This is assured if the number of production locations is finite and production at each location exhibits diminishing marginal returns to mobile factors.

If assumption 2 did not hold, capital would simply move to a new (heretofore unused) production location (in which tax rates would be zero) whenever taxes were imposed in an old one. Assumption 3 embodies the requirement that individual cities can produce output only at increasing marginal costs. Clearly, with a technology that is concave in $K_{i}$, and $L_{i}$ fixed, there is increasing marginal cost at any level of $K_{i}$ in any city $i .^{5}$

Assumption 4. All markets (land, capital and consumption good) are perfectly competitive.

Assumption 5. Both landowners and capitalists seek to maximize their claims on the homogenous consumption good.

Assumptions 4 and 5 assure that in an equilibrium in which no taxes are imposed the marginal product of capital will be equal in all cities where production takes place. Furthermore, since all economic agents in the system care only about their claims on the single good, we necd not be concerned with pricing that good. Total income going to capitalists will simply be the marginal physical product of capital (denoted $s$ ) times total capital, while landlords in each city will simply receive the residual output in the city. Denoting total output in the system as $Q$, we may write:

$$
Q=\sum_{i} q_{i}=\sum_{i} f_{i}\left(K_{i}\right), \quad i=1, \ldots, N
$$

${ }^{5}$ Both assumptions 2 and 3 have some theoretical and empirical foundation. In a standard model of urban structure [i.e. Mills $(1967,1972)$; Muth (1969)] the diseconomy of scale reflected in assumption 3 would derive from the fact that average transportation costs within a city increase with scale, even if the supply of land is perfectly elastic to a given city. Assumption 2 reflects the idea that cities develop in locations which are technically well suited to production and distribution of goods and services [see Mills (1972)]. To the extent that we observe capital flows among existing cities, rather than widespread creation of new cities, assumption 2 reflects the essential facts of the matter. 
Furthermore, from the condition for equilibrium in the capital market, and the assumption that production in each city is concave in $K$,

$$
\begin{aligned}
s & \geqq f_{i}^{\prime}\left(K_{i}\right), & i & =1, \ldots, N, \\
s & =f_{i}^{\prime}\left(K_{i}\right) \text { if } \quad K_{i} \neq 0, & i & =1, \ldots, N .
\end{aligned}
$$

Thus,

$$
s K_{i}=K_{i} f_{i}^{\prime}\left(K_{i}\right), \quad i=1, \ldots, N,
$$

where the notation $f_{i}^{\prime}\left(K_{i}\right)$ is the derivative of $f_{i}\left(K_{i}\right)$ with respect to $K_{i}$.

Thus capitalists receive a total income of

$$
W=s \bar{K},
$$

and income of landlords is

$$
R=\sum_{i} R_{i}=\sum_{i}\left(q_{i}-s K_{i}\right)=Q-W .
$$

Eqs. (2)-(4) give the equilibrium condition for the allocation of capital among cities in the absence of taxes. In the discussion of the model to follow, three different formulations for levying property taxes will be considered. Each of these formulations leads to different statements of equilibrium conditions analogous to (4). Furthermore, it will be convenient to represent property taxes as taxes on flows of current income from the taxed factors; thus the tax rates discussed below should be seen as the 'true' property tax rate multiplied by a common discount rate, and the variable $s$ is now the after tax rental price of capital. The three different formulations for property taxes are:

(1) Taxes applied to the market value of capital (with tax rates $T_{i}$ ) in which case the equilibrium condition is

$$
K_{i} f_{i}^{\prime}\left(K_{i}\right)=s\left(1+T_{i}\right) K_{i}, \quad i=1, \ldots, N
$$

(2) Taxes applied to value marginal product of capital (with tax rates $\tau_{i}$ ) in which case the equilibrium condition is

$$
K_{i} f_{i}^{\prime}\left(K_{i}\right)\left(1-\tau_{i}\right)=s K_{i}, \quad i=1, \ldots, N
$$

(3) Taxes applied to physical quantities of capital (with tax rates $t_{i}$ ) in which case the equilibrium condition is

$$
K_{i}\left[f_{i}^{\prime}\left(K_{i}\right)-t_{i}\right]=s K_{i}, \quad i=1, \ldots, N .
$$

All three formulations and their respective equilibrium conditions are equivalent for a given capital allocation. The relationships among the formulations are given by 


$$
\begin{aligned}
K_{i} f_{i}^{\prime}\left(K_{i}\right)=s\left(1+T_{i}\right) K_{i}=K_{t} s\left(1-\tau_{i}\right)=\left(s+t_{i}\right) K_{i} & \\
& i=1, \ldots, N .
\end{aligned}
$$

Thus, for any $s$, and $K_{i} \neq 0$,

$$
t_{i}=s T_{i}=s \tau_{i} /\left(1-\tau_{i}\right), \quad i=1, \ldots, N
$$

In summary, then, the model takes as data $\bar{K}$, the $N$-vector of land endowments, $L$, and $N$ production functions, $f_{i}\left(K_{i}\right)$. For any vector of taxes on physical capital, $t$, (9) gives $N$ equations for $N+1$ unknowns $\left(K_{1}, \ldots, K_{N}\right.$, and $\left.s\right)$. But the fixed $\bar{K}$ adds the condition that

$$
\sum_{i} K_{i}=\bar{K}
$$

This makes explicit the fact that $s$ and all of the $K$ 's are functions of all of the $t$ 's (which can of course be converted into T's or $\tau$ 's by using (11)). The notation $s(t)$ will be used to express the value of $s$ for a given vector of tax rates. Further, the capital allocation which solves the model when tax rates are identical everywhere will be denoted by the $N$-vector $K^{*}$, with elements $K_{1}^{*}, \ldots, K_{N}^{*}$. Aggregate output is, of course, maximized at the allocation $K^{*}$.

\section{Incidence and excess burden in the model}

This section will analyze the impact of alternative distributions of tax rates across cities under the constraint that total tax revenue in the system is held constant. Thus it may be seen as an exercise in balanced budget incidence in which the taxes being compared are different distributions of local property taxes. The incidence of a given distribution of local tax rates will be computed with respect to the state of the world obtaining when the same total revenue is raised by application of a uniform tax rate to all jurisdictions in the economy. Thus the (balanced budget) incidence of a vector of taxes $t$ on some set of actors in the model will be the willingness to pay of that set of actors for replacing the vector $t$ with a uniform tax rate which raises the same tax revenue. Balanced budget incidence so defined may be either positive or negative. ${ }^{6}$

\footnotetext{
${ }^{6} \mathrm{Absolute}$ incidence, or the total 'burden' of the tax system on a set of actors will be balanced budget incidence as defined here plus the willingness to pay of that set of actors for substituting no taxes for the uniform tax rate. The advantage of using balanced budget incidence is that it permits comparison of private tastes for states of the world in which the public budget is held constant. Unfortunately, the comparison is still imperfect, as in general we would expect the pattern of public expenditures by locality to be different under different tax regimes even if the total public budget were held constant, and we would expect actors in the system to have a willingness to pay for such differences. To deal with this issue would require that a model of demand and supply of public expenditures, locality by locality, be incorporated into the analysis. Development of such a model is well beyond the scope of this paper.
} 
The total revenue raised by a vector $t$ of taxes on capital is given by

$$
G=\sum_{i} t_{i} K_{i}(t)=\bar{K} \sum_{i} t_{i} K_{i}(t) / \bar{K}=\bar{K} t_{a},
$$

where $t_{a}$ is the average rate of taxation applying to physical quantities of capital. Clearly, the same revenue will be raised if $t_{a}$ is applied to all jurisdictions, as the physical quantity of capital in the system is constant by assumption. ${ }^{7}$ The market price of capital services under the vector of taxes $t$ will be

$$
s(t)=f_{i}^{\prime}\left(K_{i}(t)\right)-t_{i}, \quad K_{i} \neq 0 ;
$$

while the market price of capital under the uniform tax rate $t_{a}$ is given by

$$
s\left(t_{a}\right)=f_{i}^{\prime}\left(K_{i}^{*}\right)-t_{a}, \quad K_{i} \neq 0 .
$$

Thus,

$$
K_{i}\left(s(t)-s\left(t_{a}\right)\right)=K_{i}\left(f_{i}^{\prime}\left(K_{i}(t)\right)-t_{i}-f_{i}^{\prime}\left(K_{i}^{*}\right)+t_{a}\right), \quad K_{i} \neq 0 .
$$

Summing over $i$ gives the willingness to pay (of capitalists) for the tax system, $t$

$$
\bar{K}\left(s(t)-s\left(t_{a}\right)\right)=\sum_{i} K_{i} f_{i}^{\prime}\left(K_{i}(t)\right)-\bar{K} f_{i}^{\prime}\left(K_{i}^{*}\right), \quad K_{i} \neq 0 .
$$

If (17) is divided through by $\bar{K}$ it is clear that willingness to pay is positive or negative as the marginal physical product of capital in the allocation $K^{*}$ is less than or greater than the average marginal physical product of capital in the allocation $K(t)$. (The average product of capital will always be higher in the allocation $K^{*}$, but that is not the issue.) Note that if (17) is positive, then the average tax rate on capital overstates the loss of income by capital relative to a zero-tax regime. This magnitude $(s(t)-s(0))$ will be referred to below as the 'total burden' on capital of the tax system $t$. Analogously, if (17) is negative, the average tax rate understates the total burden borne by capital in the system of heterogeneous taxes. Furthermore, if (17) is positive, substitution of the average tax computed on value or marginal product $(T$ or $\tau$ ) would lower total tax revenue (i.e. both value and average marginal product will be lower under the uniform tax). The converse holds if (17) is negative. ${ }^{8}$ Only in the situation

${ }^{7}$ Where

$$
T_{a}=\sum_{i} \frac{K_{i} T_{i}}{\widetilde{K}} \text { and } \tau_{a}=\sum_{i} \frac{K_{i} \tau_{i}}{\bar{K}}
$$

it is not true in general that assessing a uniform rate $T_{a}$ on market value or $\tau_{a}$ on marginal product would raise the same revenue as would be raised if the vectors $T$ and $\tau$ were applied to their respective tax bases. See footnote 8 for a proof.

${ }^{8}$ More formally, it is asserted that

$$
\operatorname{sgn}\left[G(T)-G\left(T_{a}\right)\right]=\operatorname{sgn}\left[G(\tau)-G\left(\tau_{a}\right)\right]=\operatorname{sgn}\left[s(t)-s\left(t_{a}\right)\right],
$$

where the elements $T_{i}$ and $\tau_{i}$ of the vectors $T$ and $\tau$ are defined by equation (2) and $T_{a}$ and $\tau_{a}$ are as defined in footnote 7 . 
where (17) is zero does the average tax correctly measure the total burden on capital of a system of heterogeneous taxes. Furthermore, in this special case, all three definitions of the tax will yield the same results and raise identical revenues both in the heterogeneous tax and the uniform tax regimes.

There is an alternative formulation for equation (17) which permits a characterization of 'excise effects' in the model. Define

$$
t_{e}=s\left(t_{a}\right)-s(t)+t_{a} .
$$

It will now be proved that for each city $i$ where $K_{i} \neq 0, K_{i}(t) \gtreqless K_{i}^{*}$ as $t_{i} \lesseqgtr t_{e}$.

\section{Proof}

(1) $t_{i} \leqq t_{e}=s\left(t_{a}\right)-s(t)+t_{a}$ if and only if $s\left(t_{a}\right)+t_{a} \geqq s(t)+t_{i}$.

(2) This is equivalent to $f_{i}^{\prime}\left(K_{i}^{*}\right) \geqq f_{i}^{\prime}\left(K_{i}(t)\right)$ since $f_{i}^{\prime}\left(K_{i}^{*}\right)=s\left(t_{a}\right)+t_{a}$, and $f_{i}^{\prime}\left(K_{i}(t)\right)=s(t)+t_{i}$.

(3) Since $f_{i}^{\prime \prime}\left(K_{i}(t)\right)<0, f_{i}^{\prime}\left(K_{i}^{*}\right) \geqq f_{i}\left(K_{i}(t)\right)$ if and only if $K_{i}^{*} \leqq K_{i}(t)$.

Q.E.D.

Proof:

$$
\begin{aligned}
& G(T)-G\left(T_{a}\right)=T_{a} \bar{K}\left[s(T)-s\left(T_{a}\right)\right], \\
& G(\tau)-G\left(\tau_{a}\right)=\sum_{i} f_{i}^{\prime}(\tau) \tau_{i} K_{i}-f_{i}^{\prime}\left(K^{*}\right) \tau_{a} \bar{K}=T_{a} \bar{K}\left[s(\tau)-s\left(\tau_{a}\right)\right], \quad K_{i} \neq 0 .
\end{aligned}
$$

Thus the signs of $G(T)-G\left(T_{a}\right)$ and $G(\tau)-G\left(\tau_{a}\right)$ will be the same, respectively, as the signs of $s(T)-s\left(T_{a}\right)$ and $s(\tau)-s\left(\tau_{a}\right)$. It is therefore sufficient to prove that

$$
\operatorname{sgn}\left[s(T)-s\left(T_{a}\right)\right]=\operatorname{sgn}\left[s(\tau)-s\left(\tau_{a}\right)\right]=\operatorname{sgn} s(t)-s\left(t_{a}\right) .
$$

From eq. (11), for $K_{i} \neq 0$,

$$
t_{a}=\sum_{i} \frac{t_{1} K_{i}(t)}{\bar{K}}=\sum_{i} \frac{T_{i} s(t) K_{i}}{\bar{K}}=T_{a} s(t)
$$

Combining (v) and (15), for $K_{l} \neq 0$,

$$
s(t)-s\left(t_{a}\right)=s(t)-\left[f_{i}^{\prime}\left(K_{t}^{*}\right)-T_{a} s(t)\right]=s(t)\left(1+T_{a}\right)-f_{i}^{\prime}\left(K_{i}^{*}\right) .
$$

But $s(t)$ must equal $s(T)$, thus

$$
s(T)-s\left(T_{a}\right)=s(t)-\frac{f_{i}^{\prime}\left(K^{*}\right)}{\left(1+T_{a}\right)}=\frac{s(t)-s\left(t_{a}\right)}{\left(1+T_{a}\right)} .
$$

This proves that $\operatorname{sgn}\left[s(T)-s\left(T_{a}\right)=\operatorname{sgn}\left[s(t)-s\left(t_{a}\right)\right]\right.$. The second part of (iv) can be proved in a similar fashion. 
Because cities gain (lose) capital relative to $K_{i}^{*}$ as $t_{i}$ is less than (greater than) $t_{e}$, the excise effects of the tax system $t$ are properly computed with respect to $t_{e}$, rather than $t_{a}$. Furthermore, eq. (17) can be rewritten in terms of the relationship between $t_{e}$ and $t_{a}$. From the definition of $t_{e}$,

$$
\begin{aligned}
& s(t)-s\left(t_{a}\right)=t_{a}-t_{e}, \\
& \bar{K}\left(s(t)-s\left(t_{a}\right)\right)=\bar{K}\left(t_{a}-t_{e}\right) .
\end{aligned}
$$

Recalling eq. (17) and its interpretation, eq. (20) says that if the tax rate in tax system $t$ for which there are no excise effects is greater (less) than the average tax rate in system $t$ then capital owners will have a negative (positive) willingness to pay for system $t$ over the uniform tax $\left(t_{a}\right)$ which would raise the same revenue. Thus, the total burden of the vector of tax rates $t$ on capital is overstated (understated) by $t_{a}$ as $t_{a}$ is greater than (less than) $t_{e}$. Furthermore, there does not in general exist a uniform tax rate $t_{a}^{\prime}$ such that $s(t)$ and $s\left(t_{a}\right)$ are equal while $G(t)$ and $G\left(t_{a}\right)$ are equal. Thus it seems fruitless to look for a single 'average' tax which represents the balanced budget burden of a tax system on capital. The total burden, ignoring the public budget, is measured by $t_{e}$, rather than $t_{a}$, in that $s\left(t_{e}\right)$ if $t_{e}$ were applied uniformly, would just equal $s(t)$.

Eqs. (17) and (20) may also be interpreted to consider the shifting of taxes on capital. Clearly, if the willingness to pay of capitalists for the tax vector $t$ relative to $t_{a}$ is nonnegative (i.e. $t_{e}<t_{a}$ ), then landlords as a class bear at least all of the excess burden (which is simply $Q\left(t_{a}\right)-Q(t)$ ) of the system of taxes $t$. This follows directly from the facts that

(1) landlords' income is computed as a residual;

(2) total output is lower under the system $t$ than under the uniform tax;

(3) government revenue is the same under both systems;

(4) capitalists' income is at least as great under the heterogeneous taxes as under the uniform tax.

Thus, if capitalists and government don't lose, and output falls, landlords must lose. If capitalists gain, landlords lose more than the excess burden. It does not follow, however, that if capitalists lose landlords gain. This is because there is a loss of output associated with any heterogeneous set of tax rates, and the excess burden may be shared by the two sets of actors in the model.

In any event, statements about landlords in the aggregate imply nothing about landlords in individual cities. The excise effects of a heterogeneous system of property tax rates will lead output to rise in some cities and fall in others, even as total output falls. With the rather general assumptions made thus far concerning the production functions, it is not possible to characterize winners and losers among landlords as a function of the tax rates in their cities. 
The foregoing analysis shows that capital owners may (1) prefer heterogeneous taxes to homogeneous ones; (2) be indifferent; or (3) prefer homogeneous taxes. Table 1 provides a summary of the key relationships in the model for each of these three cases under the technology assumed in section 2 . It should be noted that case II is the only situation in which the average tax plays the role that it is asserted to play in the 'new view' of the property tax, in which it is held that (1) capital bears the average tax and that (2) excise effects occur with respect to the average tax rate. Table 1 shows that either both statements are true or neither of them are, and that in general the average tax will accurately reflect the absolute burden on capital only if exactly all of the excess burden is borne by other factors.

\section{Determinants of incidence}

All three of the cases summarized in table 1 are consistent with neoclassical production theory. Which of the three cases apply for a given economy meeting the assumptions made in section 2 will depend on the specifics of the $N$ production functions as well as on all $N$ elements of the tax vector $t$. In this section, the model is further simplified so as to permit a characterization of conditions under which each of the three cases will obtain. In particular, assumption 3 is supplemented such that all production functions are identical and are homogeneous of degree one in capital and land.

The imposition of this additional condition on the technology permits the analysis of $N$ cities of different sizes as $n>N$ cities of the same land area. For example, if city $j$ has twice the land of city $i$, we may maintain the fiction, for analytical purposes, that there are three cities with identical land endowments, $i, j$, and $j^{\prime}$, where $j$ and $j^{\prime}$ have the same tax rate. Thus the indexing of cities $(i=1, \ldots, N, \ldots, n)$ employed in this section will simply be a rewriting of the indexing used in the previous sections of the paper.

\subsection{General functional form}

With $n$ identical cities having identical production functions, eq. (17) may be rewritten

$$
\bar{K}\left(s(t)-s\left(t_{a}\right)\right)=\sum_{i=1}^{n} K_{i} f^{\prime}\left(K_{i}(t)\right)-\bar{K}\left(f^{\prime}\left(\frac{\bar{K}}{n}\right)\right) .
$$

The sign of (21) still depends on the particular configuration of tax rates in the vector $t$. However, in the neighborhood of the optimum allocation of capital $\left(K\left(t_{a}\right)\right)$ it will depend only on the (identical) production functions. In particular, it can be shown that in the neighborhood of a uniform tax ratc $\left(K_{i}=K\left(t_{a}\right)=\bar{K} / n\right)$ willingness to pay of capitalists for a system of taxes $t$ relative to the uniform tax $t_{a}$ will be positive (negative) as the second derivative 

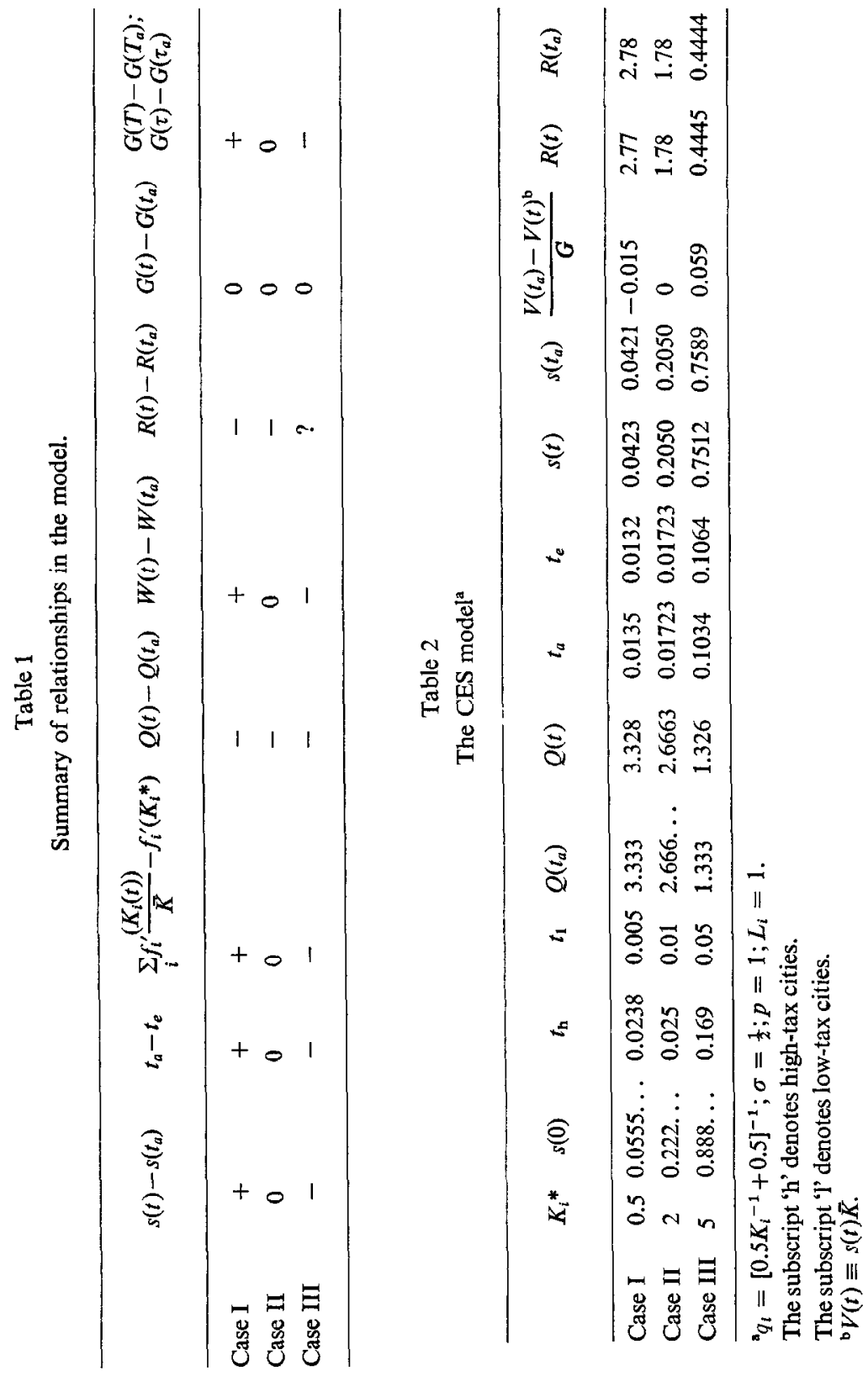
of gross payments to capital with respect to capital is positive (negative) ${ }^{9}$ Alternatively, $s\left(t_{a}\right)$ is a local maximum (minimum) as

$$
\frac{\partial^{2}}{\partial K^{2}}\left(\frac{\partial f}{\partial K} K\right) \lessgtr 0
$$

For a Cobb-Douglas production function, (22) will always be negative, and, indeed (21) will always be negative, as the share of output received by capital is constant, and output is lower than $Q^{*}$ under any allocation of capital other than $K^{*}$. For CES production functions, (22) may be positive, negative, or zero, depending on a set of conditions which will be explored later in this paper. For the class of production functions for which $K f^{\prime}(K)$ is always constant, (21) will always be equal to zero, and case II in table 1 will hold globally. However, none of the functional forms in common use have this property, and case II (the new view case) will not hold in general unless the technologies of all cities meet this condition. ${ }^{10}$

The additional assumptions on the technology made in this section of the paper also permit a more precise characterization of which landlords gain and lose relative to the state of the world under the uniform tax rate $t_{a}$. In particular, for any vector of tax rates $t$ consider the tax rate $t_{r}$ such that landlords in a city levying $t_{r}$ receive precisely the same income under the vector $t$ as they would under the uniform tax rate $t_{a}$. Assume that $t_{a}-t_{e}$ is positive and recall that this implies that $s(t)$ is greater than $s\left(t_{a}\right)$. Since city $e$ has the same output under both regimes, landlords in city $e$ will be worse off (getting the residual) under regime $t$ than under regime $t_{a}$. Thus if $t_{a}-t_{e}$ is positive, $t_{e}-t_{r}$ must also be positive (i.e. there will have to be more output for landlords' residual claim to offset the increased rental rate on capital) and in general the sign of $t_{e}-t_{r}$ will be the same as the sign of $t_{a}-t_{e}$.

Unfortunately, because of the complexity of the model, characterization of the determinants of incidence by means of general properties of the production functions cannot be accomplished except in the neighborhood of $K^{*}$. In general, the aggregate average marginal productivity of capital schedule (upon which incidence depends) is not uniquely defined by the production functions themselves. Rather, it is defined by the production functions and all of the tax rates which together determine the vector of capital allocations. For specific functional forms, however, the properties of different equilibria may be computed and analyzed explicitly as a function of the tax rates. The CES production function

\footnotetext{
${ }^{9}$ The derivations for results stated in this section are available from the author.

${ }^{10}$ The condition that $K f^{\prime}(K)$ be constant is equivalent to the condition that the marginal product of capital schedules be rectangular hyperbolas. Recalling the assumption that production functions be $\mathrm{HD} 1$, this condition is met only for functions of the form $q=c L(\ln (K / L))$, where $c$ is an arbitrary constant. To assert that the 'new view' case (case II) holds exactly, then, is to assume this functional form.
} 
is well suited to such analysis, as any of the three cases in table 1 can follow from a CES under different values of the parameters and tax rates.

\subsection{The CES case}

Retaining the assumption that each of $n$ cities have identical land area, and normalizing that land area as unity, the assumption of identical CES production functions in all cities may be stated as

$$
q_{i}=\left[\alpha K^{-\rho}+(1-\alpha)\right]^{-1 / \rho}, \quad i=1, \ldots, n,
$$

where the elasticity of substitution $(\sigma)$ equals $1 /(1+\rho)$. With some manipulation, it can be shown that for (23)

$$
\begin{aligned}
\frac{\partial^{2}}{\partial K^{2}}\left(K \cdot f^{\prime}(K)\right)= & {\left[(1+\rho) \alpha(1-\alpha) K^{-(2+\rho)} q^{(1+3 \rho)}\right] } \\
& \times\left[\rho(1-\alpha)-(1+\rho) K^{-\rho}\right] .
\end{aligned}
$$

As $\rho$ must be greater than -1 and as $\alpha$ must be less than unity, the expression in the left-hand set of brackets in (24) will always be positive. From (22), then, the uniform allocation is a local maximum (minimum) for rentals to capital as

$$
\rho(1-\alpha) \lessgtr(1+\rho) \alpha K^{-\rho} .
$$

Multiplying both sides of (25) by $q^{\rho}$ and recalling that the competitive share of capital in a CES is $(q / K)^{\rho}$, it is easily shown that (25) may be restated as

$$
(1-\sigma) \lessgtr \frac{S(K)}{S(L)},
$$

where $S(K)$ and $S(L)$ are the competitive factor shares.

Note that if $\rho$ is negative ( $\sigma$ greater than one) the uniform allocation of capital must be a local maximum for gross capital rentals.

A similar procedure can be used to show that gross payments to land will be maximized (minimized) at the uniform capital allocation as

$$
S(L) / S(K) \gtrless(1-\sigma) .
$$

Combining conditions (26) and (27) it is clear that the uniform allocation can never be a local minimum for both factors. It will be a local maximum for both factors where

$$
S(K) / S(L)>1-\sigma ; \quad S(L) / S(K)>1-\sigma .
$$


This condition always holds where the elasticity of substitution is equal to or greater than unity.

Again, conditions (26) through (28) hold only in the neighborhood of the uniform capital allocation. For other allocations, the incidence of capital taxes will depend both on the parameters of the production function and on the specific distribution of tax rates. Equilibrium requires that for each city $i$,

$$
\alpha K^{-(1+\rho)}\left[\alpha K^{-\rho}+(1-\alpha)\right]^{-(1+\rho / \rho)}-t_{i}=s, \quad i=1, \ldots, n,
$$

Thus, for any pair of cities $i$ and $j$,

$$
\begin{aligned}
t_{j}=\alpha\left(\frac{q_{j}\left(K_{j}\right)}{K_{j}}\right)^{1+\rho}-\alpha\left(\frac{q_{i}\left(K_{i}\right)}{K_{i}}\right)^{1+\rho}+t_{i}, \\
\quad i=1, \ldots, n, j=1, \ldots, n .
\end{aligned}
$$

Eq. (30) may be solved implicitly for any $K_{i}$ as a function of a given $K_{j}$ and the two relevant tax rates. In practice, it is easy to set the $K$ 's so as to add up to a given $\bar{K}$, set one tax rate, and solve for all of the other tax rates - hence the form of eq. (30). Table 2 revises table 1 for three cases of CES production. In all three cases there are assumed to be only two cities, one of which taxes at a high rate, and the other at a lower rate. In all three cases both the elasticity of substitution and the parameter $\alpha$ assume a value of one-half.

The examples presented in table 2 confirm the analytical results derived earlier in the paper. Perhaps the most interesting feature of the examples is that the entries in the column $\left(V\left(t_{a}\right)-V(t)\right) / G$ take on values of both signs and have magnitudes that are quite different from zero. The absolute value of entries in that column measures the difference between the total burden of a given tax system $t$ and that of a uniform tax raising the same revenue as a fraction of total tax revenue. This may be interpreted as the percentage error associated with using the average rate of capital taxation to measure the burden of a system of property taxes on capital.

\section{Conclusions and implications}

The purpose of this paper has been to construct and analyze a model of an economy in which a mobile factor is taxed at different rates in different locations. The main result of that exercise has been a demonstration that the relationship between the general effects of such taxation and the specific effects, locality by locality, is not easily characterized. The reason for this is that these effects are not independent. Alternative schemes of local capital taxation raising identical revenues will not in general have identical excess burdens; nor will distributions of such excess burdens across factors and across localities be independent of the particular form of the taxing schemes. Further, even if all production 
functions are identical and total tax revenue is fixed, the properties of the production functions alone do not provide sufficient information to compute the magnitude and distribution of excess burdens. Thus, conceptual separation of the incidence of local capital taxes into 'average' and 'excise' effects is an approximation at best, and, as is indicated by the examples in table 2, it may not be a very good approximation.

Drawing of direct policy conclusions from the model presented here is inhibited by the fact that the model is of only one sector and contains only one mobile input. To approach the 'real world', one would want, as Aaron (1975) has suggested, a model with two mobile factors (labor and capital) and two sectors (local and national goods). Such a model could be developed using the general framework employed in this paper. The analysis would be much more complicated, however, and it would probably be necessary to resort to extensive simulation in order to derive results analogous to those derived here. Thus, the specific results derived above concerning the role of factor shares in determining willingness to pay in a two factor CES model, for example, have no obvious policy implications - they simply illuminate the workings of the model.

The fact that the model used here has only one mobile factor and one produced good also prohibits explicit consideration of the implications of heterogeneous property taxes within an urban area for the efficiency with which public goods are provided and land is used. Both the literature arising from the Tiebout hypothesis and the literature on the effects of property taxation within an urban area involve two mobile factors (labor and capital) and two produced goods (housing and a composite). ${ }^{11}$ Development of a model which could comprehend both intrametropolitan equilibria and intermetropolitan equilibria would be of great value in that analytical implications derived from such a model would be directly applicable for policy purposes, while those derived from this model are at best only suggestive.

In spite of these difficulties, two results from the model used here can be expected to generalize to more complicated specifications, and they are of considerable policy significance:

(1) Unless there is perfect Tiebout equilibrium, such that there is no excess burden associated with property taxes, holders of mobile factors may prefer a system of heterogeneous tax rates to a uniform tax rate raising the same revenue - even though the latter case leads to higher total output. Put another way, the excess burden of the heterogeneous tax system may be shifted more than one hundred percent onto fixed factors. (The reverse may also hold, but is less surprising.)

(2) The tax rate at which holders of fixed factors will break even if a revenue preserving uniform tax is substituted for a heterogeneous set of tax rates may

\footnotetext{
${ }^{11}$ See Hamilton (1975) for a representative example of the recent Tiebout literature. See Polinsky and Rubinfeld (1978) for a spatial model of an urban area with property taxation.
} 
be higher or lower than the average tax rate. Thus, permanent residents of cities (landholders) would have to perform fairly difficult computations in order to establish whether they would win or lose if such a policy change were adopted.

Finally, it should be noted that this model, which is basically an extension of the Harberger model of general equilibrium incidence, can be revised to consider other taxation problems in which the relationship between an economy and its constituent parts is the key issue. One could look at changes in state level taxes in a national economy, at changes in national taxes in the international economy, and other issues of this type. The difficulty in such modelling lies in careful specification of the mobility of factors across different political boundaries. The simplest possible assumption has been made here, but I would expect that more realistic assumptions can be fruitfully handled within the same general structure.

\section{References}

Aaron, Henry J., 1975, Who pays the property tax - A new vicw (Brookings, Washington). Courant, Paul N. and Daniel L. Rubinfeld, 1978, On the measurement of benefits in an urban context: Some general equilibrium issues, Journal of Urban Economics 5, forthcoming.

Hamilton, B., 1975, Zoning and property taxation in a system of local governments, Urban Studies 12, 205-211.

Harberger, A.C., 1962, The incidence of the corporation income tax, Journal of Political Economy 70, 215-240.

Mills, E.S., 1967, An aggregative model of resource allocation in an urban area, American Economic Review 57, 197-210.

Mills, E.S., 1972, Urban economics (Scott Foresman, Glenview, IL).

Mieszkowski, Peter, 1969, Tax incidence theory: The effects of taxes on the distribution of income, Journal of Economic Literature 7, 1103-1124.

Mieszkowski, Peter, 1972, The property tax: An excise tax or a profits tax, Journal of Public Economics 1, 73-96.

Muth, R., 1969, Cities and housing (Chicago).

Polinsky, A.M., and D.L. Rubinfeld, 1978, The long-run effects of a residential property tax and local public services, Journal of Urban Economics, forthcoming. 